Article

\title{
Preparation and Characterization of EG-Chitosan Nanocomposites via Direct Exfoliation: A Green Methodology
}

\author{
Christian Demitri ${ }^{1, *}$, Anna Moscatello ${ }^{1}$, Antonella Giuri ${ }^{1}$, Maria Grazia Raucci ${ }^{2}$ and \\ Carola Esposito Corcione ${ }^{1}$
}

Received: 26 October 2015; Accepted: 1 December 2015; Published: 9 December 2015

Academic Editor: Frank Wiesbrock

1 Department of Engineering for Innovation, University of Salento, Via Monteroni, km 1, 73100 Lecce, Italy; anna.moscatello@unisalento.it (A.M.); antonella.giuri@unisalento.it (A.G.); carola.corcione@unisalento.it (C.E.C.)

2 Institute of Polymers, Composites and Biomaterials (IPCB), National Research Council of Italy Mostra d'Oltremare Pad.20, Viale Kennedy 54, 80125 Naples, Italy; mariagrazia.raucci@cnr.it

* Correspondence: christian.demitri@unisalento.it; Tel.: +39-0832-297-238; Fax: +39-0832-297-240

\begin{abstract}
In this study, free-standing expanded graphite chitosan (EG-chitosan) nanocomposite films have been prepared using a novel green and simple preparation method, starting from a commercial expandable graphite (GIC). The in situ exfoliation of GIC by a solvent-free sonication method was monitored as a function of the process parameters using X-ray diffraction (XRD), transmission electron microscopy (TEM), dynamic light scattering (DLS) and UV-visible transmittance (UV-VIS) analyses. The optimal process parameters were selected in order to obtain an efficient dispersion of EG in chitosan solutions. The effective EG amount after the in situ exfoliation was also determined by thermogravimetric analyses.
\end{abstract}

Keywords: nanocomposites; chitosan; graphite; green direct exfoliation

\section{Introduction}

Polymer composites reinforced with inorganic fillers of dimensions in the nanometer range (less than $100 \mathrm{~nm}$ ), known as nanocomposites, have attracted great interest from researchers, due to unexpected "synergistic" properties derived from the two components. The most studied polymer nanocomposites are composed of thermoplastic or thermosetting matrix, clay [1-7], or carbon nanotubes (CNTs) and graphene nanoplatelets [8-21].

The discovery of graphene combines extraordinary physical properties, and its ability to be dispersed in various polymer matrices leads to a new class of polymer composites. Graphene is an atomically thick, two-dimensional (2-D) sheet composed of sp2 carbon atoms arranged in a regular hexagonal pattern. It can be considered as the building block of all other graphitic carbon allotropes of different dimensionality [22]. Montmorillonite and graphite, once exfoliated in a polymer matrix, show a layered structure characterized by a high aspect ratio, defined as the ratio between the in-plane dimension and the thickness of the reinforcement $[23,24]$. Polymer matrices reinforced with graphene platelets present higher electrical and thermal conductivity sharing with those reinforced with clay platelets improved strength, modulus, heat distortion temperature and barrier properties [25].

The synthesis of expandable graphite (GIC) as well as graphene sheets is well documented in the literature [25-27]. Neat graphite (NG) is first converted to intercalated or expandable graphite through chemical oxidation in the presence of concentrated $\mathrm{H}_{2} \mathrm{SO}_{4}$ or $\mathrm{HNO}_{3}$. Expanded graphite is then obtained by expansion and exfoliation of GIC by rapid heating in a furnace above $600{ }^{\circ} \mathrm{C}$. 
A number of studies have been conducted on expanded graphite reinforced conductive polymer composites [27-31]. So far, investigations have been carried out on thermoplastic materials such as polystyrene [28] and poly(methyl methacrylate) (PMMA) [29]. These composites were prepared via in situ polymerization or solution compounding looking mainly at their electrical properties.

Graphene-based sheets have also been tested as possible nanocarriers for delivering drugs [32] and also as functional biomaterials [33,34]. Shen et al. [35] reported graphene oxide-based biocomposites through diimide-activated amidation and found that the covalently bonded biomaterials retained their bioactivity while Dai et al. [36-38] reported non-toxic nano-graphene oxide modified with poly(ethylene) glycol (PEG) could delivery water-insoluble cancer drugs.

Chitosan is a linear polysaccharide consisting of $\beta(1,4)$-linked D-glucosamine residues (deacetylated unit) with a variable number of randomly located $\mathrm{N}$-acetyl-glucosamine groups (acetylated unit). As one of the most abundant natural biopolymers on earth, it is extensively used for food packaging, biosensors, water treatment, and drug delivery [39]. It has been reported that chitosan-based biomaterial could promote chondrogenesis [40-42].

Despite its unique physical properties, the mechanical properties of pristine chitosan are insufficient to satisfy a wide range of applications. A lot of researchers demonstrate that graphene-oxide (GO) can be evenly dispersed in chitosan matrix, even through the formation of amide linkages between them [25,43-47].

Since the chitosan can provide a biocompatible, transferable, and implantable condition for cell culture $[47,48]$, some authors also evaluate the viability of cells on GO-chitosan composite film using C3H10T1/2 cells, for potential applications in growth of articular cartilage [49].

However, there is a very limited literature on the development of chitosan matrices reinforced with thin graphene sheets (or stacks of several graphene sheets), obtained starting from expandable graphite. In this paper, a novel green-based technique to obtain exfoliated EG into chitosan solutions was achieved. The goal was to determine the optimum process conditions to create EG-chitosan nanocomposites without the use of any organic solvent. To this aim, different process parameters were investigated by using several structural, morphological and thermal analyses.

Furthermore, since the EG-chitosan films are biologically compatible and mechanically reinforced, they could have additional applications in different functional biomaterials. Based on the obtained results, it is envisaged that the EG-chitosan films will pave the way for next-generation graphene applications in the realm of functional biomaterial or food packaging applications. Further mechanical and barrier (oxygen and water permeability) analyses are still in progress, in order to verify the potential application fields of the novel EG/chitosan composites.

\section{Experimental Section}

\subsection{Materials}

Expandable graphite flakes (GIC), intercalated with a mixture of sulfuric acid and nitric acid, were obtained from Anthracite Industries (EG 3772, Sunbury, PA, USA). A content of $3.5 \mathrm{wt} \%$ of intercalate was reported on the technical data sheet. GIC, after a rapid heating at $700{ }^{\circ} \mathrm{C}$ for $2 \mathrm{~min}$ in an oven, is transformed in expanded graphite (EG) characterized by a volume of about $250 \mathrm{~cm}^{3} / \mathrm{g}$ and a carbon content of about $99.5 \%$, by following a simple procedure previously assessed [24,50-52].

Chitosan, from crab shell, with low molecular weight (LMW) (Average molecular weight of $100 \mathrm{kDa}$, Deacetylation degree of 85\%), glacial acetic acid (AA), were purchased from Sigma Aldrich (Milan, Italy) and used without further purification. All solutions were prepared using water from reverse osmosis purification system (General Waters, Bologna, Italy) and filtered through a $0.45 \mathrm{~mm}$ Milipore syringe filter. Chitosan solutions were prepared by suspending $1 \mathrm{~g}$ of chitosan in $100 \mathrm{~g}$ of water/AA $(1 \% v / v)$ solutions in glass flasks. 


\subsection{EG-Chitosan Nanocomposites Preparation}

The graphite precursor was obtained by sonicating EG in chitosan solutions at different time points ( 0 h-control, 2, 4, 6 and $8 \mathrm{~h}$ ) using a Bioruptor (Diagenode Inc., Denville, NJ, USA). After the sonication step, the solutions were centrifuged at $5000 \mathrm{rpm}$ for $20 \mathrm{~min}$ in order to collect supernatant solution containing the polymer and the precursor.

The EG-chitosan (EG_CS) films were then prepared using the solvent evaporation technique. For each time point, film forming solutions were then poured on PTFE (Teflon) plates and left to dry for $24 \mathrm{~h}$ at $25^{\circ} \mathrm{C}$, until the total evaporation of the solvent. The dried films were peeled from the plate and maintained at $25{ }^{\circ} \mathrm{C}$. Neat chitosan films, prepared following the same sonication procedures at the same time points, were used as a control in the different analyses. In Table 1 the sample code and compositions of all the suspensions prepared are reported.

Table 1. Sample code and compositions of EG-chitosan (EG_CS) composites.

\begin{tabular}{cccc}
\hline Sample code & Chitosan solution $\mathbf{( m L )}$ & Sonication time (h) & EG (mg) \\
\hline CS (control) & 3 & 0 & na \\
EG_CS 2h & 3 & 2 & 1.5 \\
EG_CS 4h & 3 & 4 & 1.5 \\
EG_CS 6h & 3 & 6 & 1.5 \\
EG_CS 8h & 3 & 8 & 1.5 \\
\hline
\end{tabular}

The effective EG weight fraction for each sample has been calculated by means of thermogravimetric analysis as described into the experimental section.

\subsection{Experimental Techniques}

\subsubsection{X-Ray Diffraction}

Wide-angle X-ray diffraction (XRD) was collected on a ULTIMA + (RIGAKU, Ettlingen, Germany), using $\mathrm{Cu} \mathrm{K} \alpha$ radiation in reflection mode. Samples of expandable graphite (GIC), expanded graphite (EG), and EG-chitosan based nanocomposites (2-8 h of sonication) were step-scanned at room temperature from values of $2 \theta$ ranging from $5^{\circ}$ to $60^{\circ}$. The samples were held in the diffractometer using a socket glass sample holder, and d-spacings were calculated using Bragg's law.

\subsubsection{TEM}

The transmission electron microscopy (TEM) images were taken by a Hitachi H-9000NAR (Tokyo, Japan) model instrument operated at an accelerating voltage of $100 \mathrm{kV}$. Samples for TEM imaging were prepared by placing a drop of the suspensions (the suspensions were diluted in deionized water and dispersed by ultrasonic waves before use) onto carbon coated copper grids, dried in air and loaded into the electron microscope chamber.

\subsubsection{DLS}

The size of the graphite particles contained in the liquid mixtures, corresponding to each nanocomposite formulation prepared, were measured by Dynamic Light Scattering analysis (DLS Zetasizer-Malvern Instruments, Worcestershire, UK). Samples were prepared by diluting approximately $1 \mathrm{~mL}$ of sonicated native solution after each step in $9 \mathrm{~mL}$ of distilled water. Ten consecutive measurements were performed on each sample, thus reducing the influence of random errors. At the end of the above-mentioned measurements, the software was able to calculate the mean value and the polydispersion index for each sample. 


\subsubsection{UV-VIS}

Transmittance spectra of the unfilled and filled liquid mixtures (diluted in distilled water by $1 / 10 v / v)$ were recorded at normal light incidence in the wavelength range of 300-1100 nm with a Varian Cary 50 SCAN UV-Vis spectrophotometer (Agilent Technologies, Santa Clara, CA, USA). Unfilled sonicated chitosan solutions were used as a reference for each time point.

\subsubsection{Thermal Analyses (TGA/DSC1)}

The solid residual of each unfilled and filled film was calculated by thermogravimetric analysis (TGA/DSC1 Star and System, METTLER Toledo, Zürich, Switzerland). To this aim, the samples were heated from room temperature up to $800^{\circ} \mathrm{C}$ at $10^{\circ} \mathrm{C} / \mathrm{min}$ in nitrogen atmosphere.

\section{Results and Discussion}

The results of XRD, performed on graphite flakes of EG 3772 before (GIC) and after the expansion (EG) and sonication in chitosan (EG_CS), for the minimum and maximum sonication time (EG_CS 2h and EG_CS 8h), are reported in Figure 1 and summarized in Table 2.

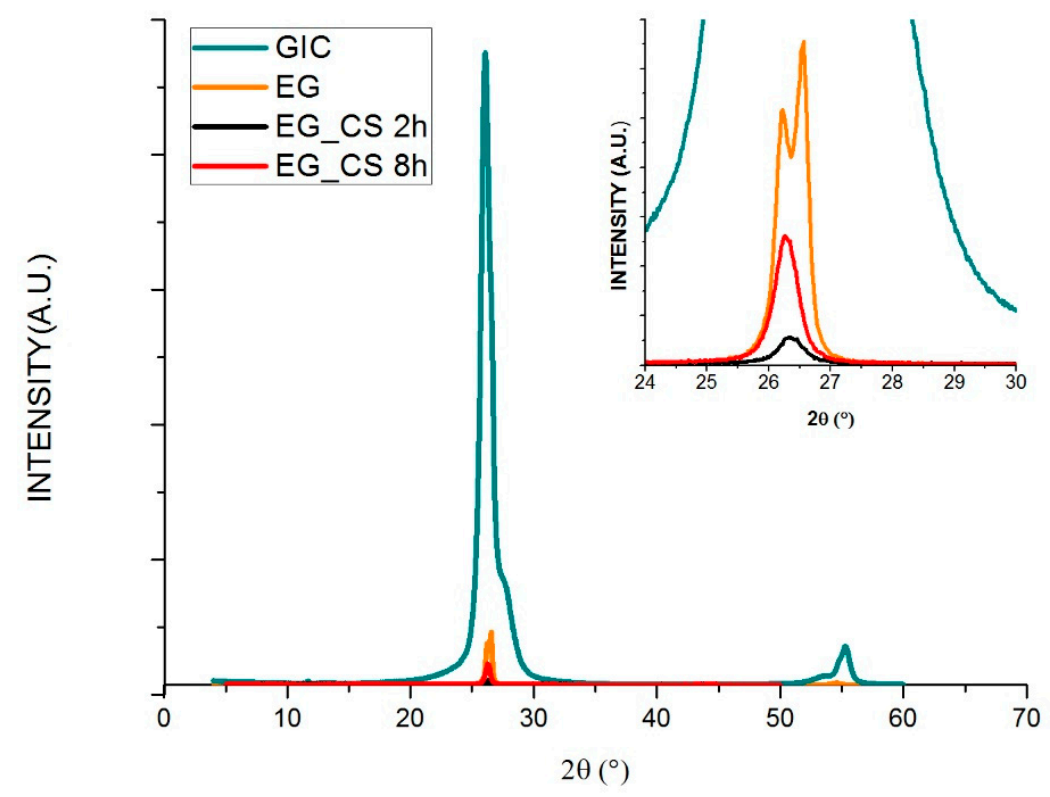

Figure 1. XRD spectra of graphite flakes of EG 3772 before (GIC) and after the expansion (EG) and sonication in chitosan (EG_CS), for the minimum and maximum sonication time (EG_CS $2 \mathrm{~h}$ and EG_CS 8h).

Table 2. XRD parameters obtained from data reported in Figure 1.

\begin{tabular}{ccc}
\hline Sample code & $\mathbf{2 \theta}\left(^{\circ}\right)$ & $\boldsymbol{d}(\mathbf{n m})$ \\
\hline GIC & $26.02 ; 26.55$ & 0.336 \\
EG & $26.05 ; 26.56$ & 0.335 \\
EG_CS 2h & 26.36 & 0.337 \\
EG_CS 8h & 26.28 & 0.338 \\
\hline
\end{tabular}

Intercalated graphite platelets show an intense peak at $2 \theta=26.02^{\circ}$ (corresponding to $d=0.336 \mathrm{~nm}$, attributed to the intercalation of sulfuric acid) and only a shoulder at $2 \theta=26.54^{\circ}$. After the expansion, XRD analysis on EG shows a reduced intensity of the peak at $2 \theta=26.05^{\circ}$, resulting from sulfuric acid decomposition, leading to a lower amount of intercalated graphene. In the case of expanded and sonicated graphite in chitosan (EG_CS 2h, EG_CS 8h), the position of the second peak 
remained roughly the same; on the other hand, the peak at $2 \theta=26.05^{\circ}$ vanished, as a consequence of a complete disaggregation of intercalated galleries, independently of the time sonication. This latter result suggests that the sonication of the EG may lead to an increase of the aspect ratio of the nanofiller, and that the time of sonication does not affect the grade of exfoliation.

The morphology of expandable graphite flakes before (GIC) and after (EG) expansion has been reported in a previous work [24]. The diameter of GIC platelets is approximately $400-600 \mu \mathrm{m}$. The intercalated graphite platelets were expanded a few hundred times during high-temperature treatment. The microstructure observed for the EG sample, obtained after the heat-treatment of the intercalated graphite flake at $700{ }^{\circ} \mathrm{C}$, exhibits a worm-like or an accordion-like shape composed of multiple nano-scaled platelet layers held together at their edges. These long, porous, distorted structures are characterized by a length up to 300 times higher than the initial platelet thickness, while their diameter remains almost unchanged.

Conversely, the morphology of EG-chitosan composites, evaluated by TEM analyses is reported in Figure 2A-D. TEM analysis revealed a large quantity of flakes with different structures varying the sonication time. In particular, TEM image of EG_CS composites after $2 \mathrm{~h}$ of sonication in Figure 2A shows a small quantity of monolayer EG flakes. A larger quantity of flakes with few layers (including some bilayers and tri-layers) can be observed when the sonication time is increased (Figure 2B). Furthermore, in Figure 2C,D, a transparent sheet-like structure can be found indicating the presence of monolayers. These images suggest that the selected sheet could be arranged in a single crystal and the obtained products include monolayer graphene sheets [53]. In general, the majority of these few-layer flakes had lateral dimensions of $\sim 1 \mu \mathrm{m}$. Thicker flakes, with more than a few graphene layers per flake, were larger, ranging up to $3 \mu \mathrm{m}$ in diameter.
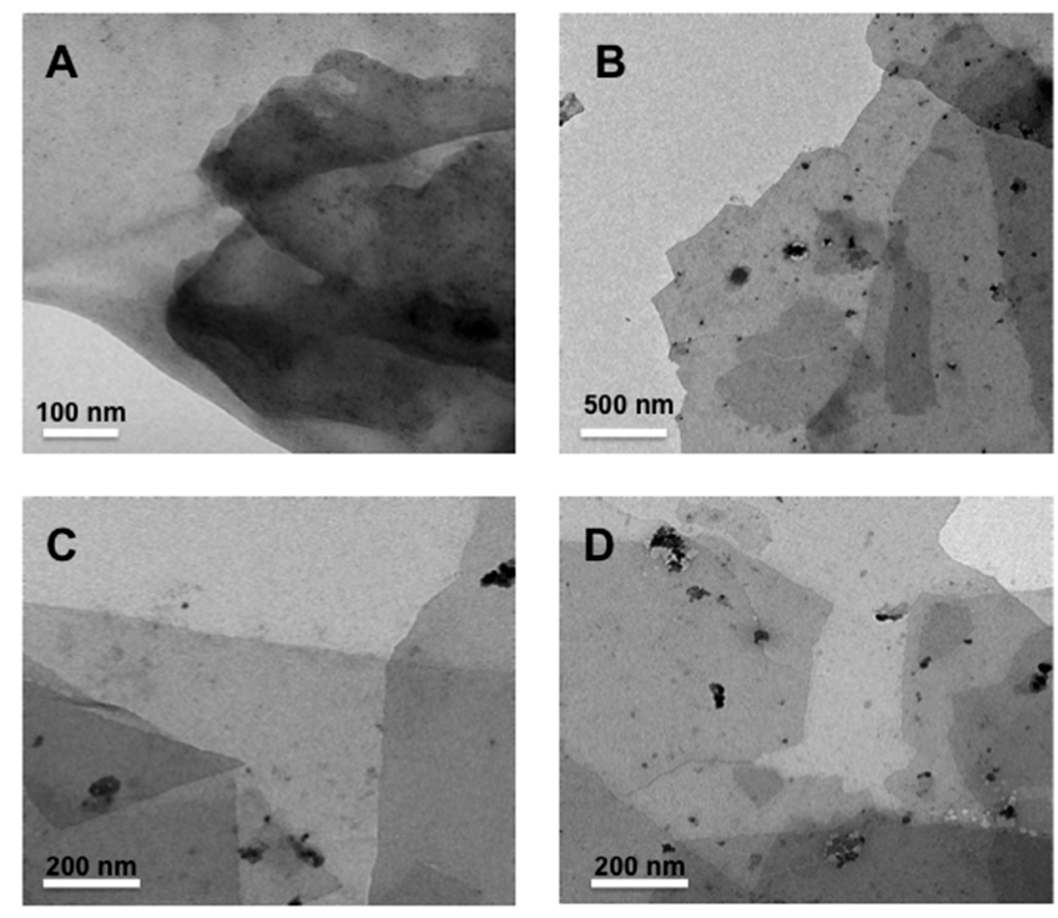

Figure 2. TEM images of EG-Chitosans at different sonication time: (A) $2 \mathrm{~h}$; (B) $4 \mathrm{~h}$; (C) $6 \mathrm{~h}$; and (D) $8 \mathrm{~h}$.

The XRD analysis, which can give relevant results on the intercalation properties of bulky samples, does not provide information either on the aspect ratio of EG or on the presence of exfoliated lamellae. The first issue is also critical for SAXD analysis, which can only give information on the average lamellar spacing. TEM analysis suggests that actually two factors play a significant role in nanocomposite: the degree of intercalation (defined by the inter-laminar spacing, as revealed by XRD 
analysis), and the degree of dispersion (defined by the average number of lamellae in each stacking), which cannot be determined by XRD analysis. Intercalated structures with the same basal spacing are characterized by similar XRD spectra, although the degree of dispersion can be different, as well as the resultant macroscopic physical and mechanical properties [6]. According to these observations, further experiments were conducted to analyze the differences between nanocomposites with similar XRD spectra (Table 2 and Figure 1) but presenting different macroscopic properties.

The characterization of the particle size distribution of the liquid nanocomposites mixtures was also performed using DLS technique. The average particle dimension measured by DLS for EG-chitosan formulation, sonicated at different time points, ranging from 2 to $8 \mathrm{~h}$ is reported in Figure 3. The chitosan nanocomposite formulations showed an average EG particle dimensions ranging between 270 to $530 \mathrm{~nm}$, as a function of the sonication times. In particular, the lower particles dimension was found in the case of the EG-chitosan formulation sonicated for $6 \mathrm{~h}$. These results are in agreement with TEM analyses, and put in evidence that the grade of exfoliation of EG in the chitosan matrix clearly depends on the sonication time, even if the XRD analyses were not able to reveal this aspect.

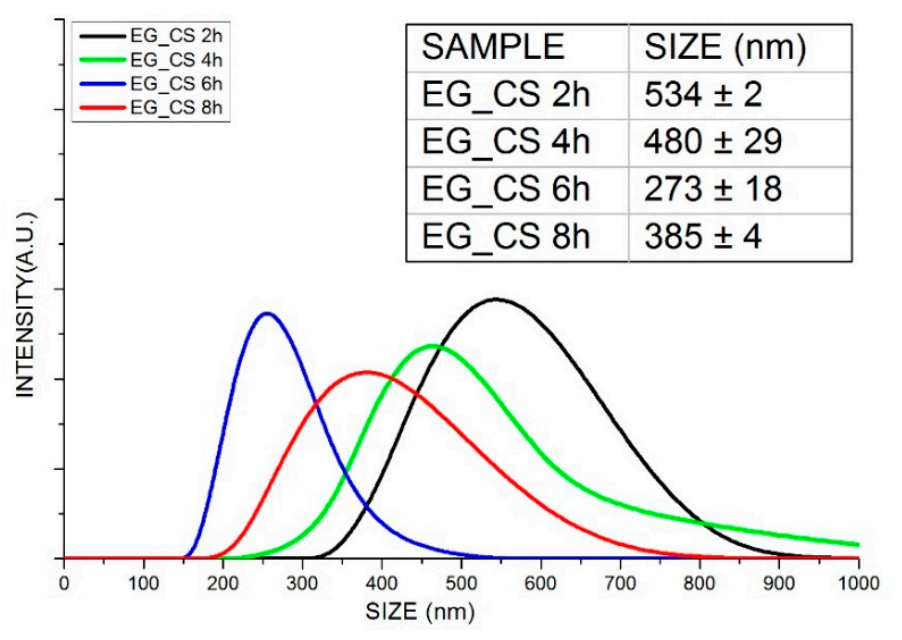

Figure 3. DLS curves of EG-chitosan formulations with the respective EG dimension.

It is also evident that the smallest particle size, showed by DLS data and reported in the table of Figure 3, reversibly increased at $8 \mathrm{~h}$. This latter result is evidence that a time sonication longer than $6 \mathrm{~h}$ could cause structural defects in the chitosan matrix, with the formation of graphite micrometric aggregates [54].

To have further evidence of the influence of the sonication time on the grade of exfoliation and dispersion of the EG nanoparticles in the chitosan matrix, UV-visible transmittance (UV-VIS) measurements were also performed on each water dilute EG-chitosan suspension. The results are reported in Figure 4. UV-VIS absorption spectra of the EG-chitosan dispersions at different exfoliation time are presented. In literature is reported that graphene has got a peak centered at $300 \mathrm{~nm}$ corresponds to the $\mathrm{C}=\mathrm{C}$ of graphene sheet [54]. Increasing in absorbance values is correlated with a further exfoliation of EG in the solution. Thus, the absorbance of graphene dispersions after $2 \mathrm{~h}$ sonication is not effective in the exfoliation process. 


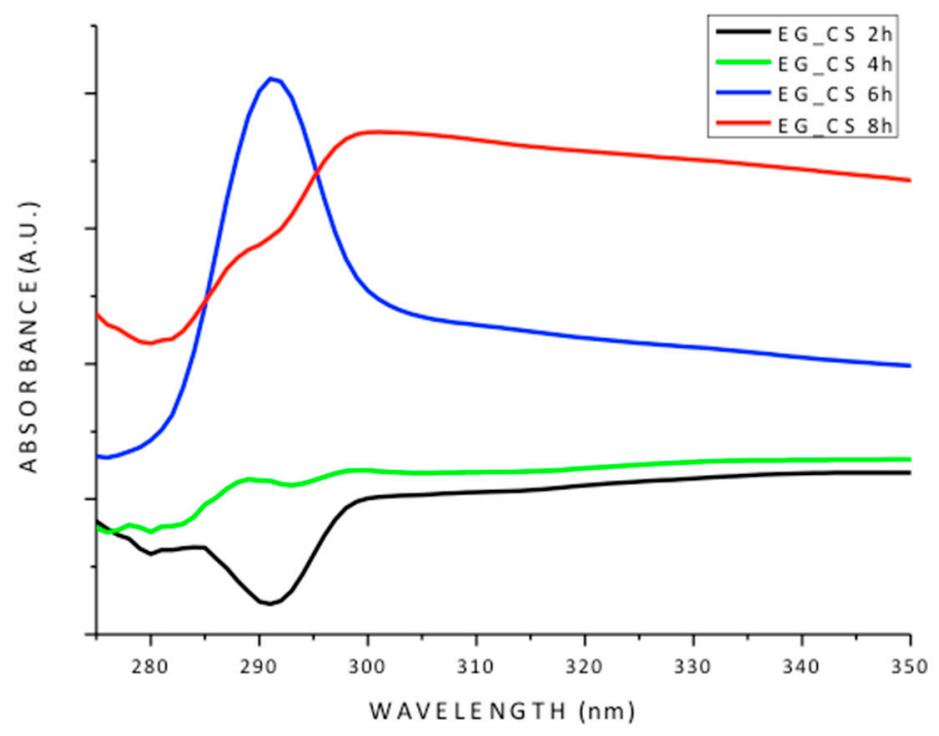

Figure 4. UV-visible transmittance spectra of the water dilute EG-chitosan formulations.

Correlating the absorbance with the concentration of the synthesized EG-chitosan samples, it is evident that the absorbance increased remarkably with the increasing sonication time with a maximum for $6 \mathrm{~h}$ sonication. In contrast, $8 \mathrm{~h}$ sonication seems to have a destructive effect on the EG sheets. This result is in agreement with DLS analyses, and confirms that $6 \mathrm{~h}$ of sonication represent the more suitable time to obtain a good exfoliation and dispersion of the filler in the chitosan matrix.

The EG-chitosan films, prepared using the solvent evaporation technique, were characterized by thermal analysis in order to calculate the weight fraction of EG contained in each film, obtained with a different sonication time. The TGA curves of each EG-chitosan composite are reported in Figure 5A.
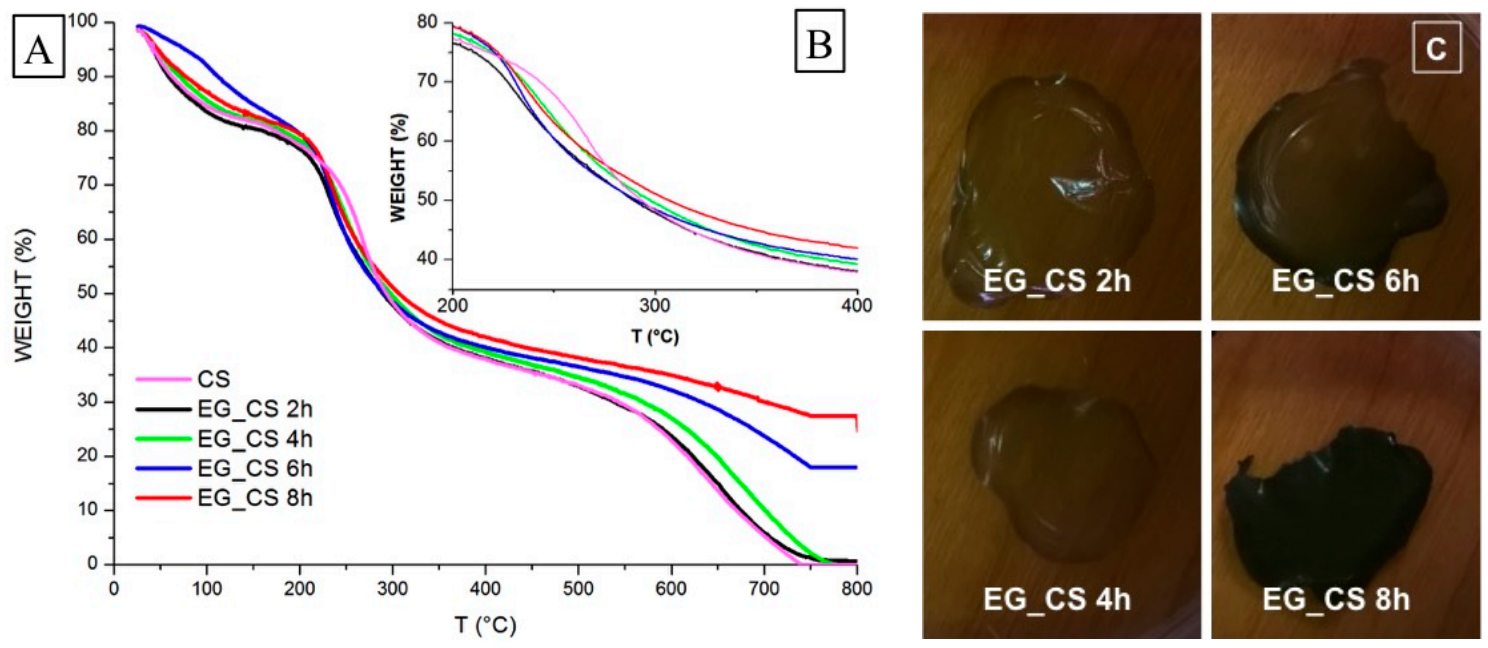

Figure 5. (A) TGA/DSC1 curves of unfilled and filled EG-chitosan composites; (B) Enlargement of TGA/DSC1 curves in a temperature range of $200-400{ }^{\circ} \mathrm{C}$; (C) pictures of the unfilled and filled EG-chitosan composite films.

All films showed three stages of weight loss $\left(100-200{ }^{\circ} \mathrm{C} ; 200-400^{\circ} \mathrm{C}\right.$; and $\left.500-700^{\circ} \mathrm{C}\right)$. Referring to the stages of weight losses illustrated by the pure chitosan (CS), the first weight loss started at about $100{ }^{\circ} \mathrm{C}$ and was attributed to the evaporation of absorbed water; the second and third stages $\left(200-400{ }^{\circ} \mathrm{C}\right.$ and $\left.500-700{ }^{\circ} \mathrm{C}\right)$ were assigned to the decomposition of chitosan, vaporization and elimination of volatile products due to pyrolysis of polysaccharides [55]. Similarly, EG-chitosan 
composites showed the same three-stage degradation behavior. The first stage, between 100 and $200{ }^{\circ} \mathrm{C}$, should be associated with the loss of water in the chitosan. For the EG-chitosan composites, it was not possible to observe an increase of initial degradation with the increase sonication time, being indicative of the unchanged thermal stability of the chitosan, in presence of EG, even at higher sonication times. The mass residual percentage of chitosan and EG-chitosan composites measured, from TGA curves at the temperature of $800{ }^{\circ} \mathrm{C}$, are reported in Table 3. The mass residual percentage at $800{ }^{\circ} \mathrm{C}$ was found to be about $0.02 \%$ and up to $24.64 \%$ for neat chitosan and EG_CS $8 \mathrm{~h}$, respectively. This highlighted that starting from the same amount of EG added to the chitosan matrix and increasing the time of sonication led to a substantial increase of the final content of EG in the chitosan matrix, in particular in correspondence of 6 and $8 \mathrm{~h}$ of sonication. The high amount of EG contained in the EG_CS $6 \mathrm{~h}$ and EG_CS $8 \mathrm{~h}$ is also evidenced by the black color of the films, as visible in the picture of Figure 5B.

Table 3. Final solid residual and EG weight fraction measured from TGA analysis.

\begin{tabular}{ccc}
\hline Sample code & Final solid residual (\%) & EG weight fraction (\%) \\
\hline CS (control) & 0.02 & na \\
EG_CS 2h & 0.63 & 0.61 \\
EG_CS 4h & 0.89 & 0.87 \\
EG_CS 6h & 12.05 & 12.03 \\
EG_CS 8h & 24.64 & 24.68 \\
\hline
\end{tabular}

\section{Conclusions}

In this work, we have developed a method for the direct exfoliation of EG in the presence of chitosan solution for the preparation of EG-chitosan nanocomposites. The aim of the study was to disperse graphite in water solution of chitosan with the aid of ultrasonication in a solvent-free and green environment. This process results in large-scale exfoliation to give larger quantities of multilayer graphene stacks and monolayer graphene in the case of extended time of treatment. XRD analyses seem to be ineffective in determining the grade of exfoliation of EG-chitosan formulations. On the other hand, UV-VIS, TEM and DLS analyses provide significant information about the dimensions, morphology and chemical structure of exfoliated EG, dispersed in the liquid chitosan matrix. The characterization of dilute EG-chitosan dispersions by UV-VIS suggests the absence of defects with a maximum in the yield of the process for the sample sonicated for $6 \mathrm{~h}$. The dispersions are reasonably stable, and they can be used to form semi-transparent films by solvent casting techniques. We showed that the selected exfoliation method for EG-chitosan in aqueous solution is an effective route for a green synthesis of chitosan-graphene nanocomposites. These preliminary results could be a promising starting point for a following study on the application of these novel composites to different technological fields. As an example, in the future, the addition of different natural polymers as the incorporation of selected active natural molecules will be evaluated with the aim to create a versatile platform for different applications. Biomedical applications could also be envisioned, thanks to chitosan osteogenic properties. A potential use of the EG-chitosan composites for food packaging applications will finally be explored, by measuring permeability to gasses and vapors, such as oxygen and water, mechanical properties, and water resistant and antifungal properties of the of EG-chitosan films.

Acknowledgments: The authors wish to thank Cristina Del Barone from the Laboratory of Electron Microscopy "LaMEST" of IPCB, CNR for the technical assistance with the TEM analysis.

Author Contributions: Christian Demitri and Carola Esposito Corcione conceived the study, designed the experiments and wrote the paper; Anna Moscatello performed the experiments and analyzed the data; and Antonella Giuri and Maria Grazia Raucci performed the X-ray and TEM analyses, respectively.

Conflicts of Interest: The authors declare no conflict of interest. 


\section{References}

1. Ruggerone, R.; Plummer, C.J.G.; Herrera, N.N.; Bourgeat-Lami, E.; Månson, J.A.E. Highly filled polystyrene-laponite nanocomposites prepared by emulsion polymerization. Eur. Polym. J. 2009, 45, 621-629. [CrossRef]

2. Greco, A.; Corcione, C.E.; Strafella, A.; Maffezzoli, A. Analysis of the structure and mass transport properties of clay nanocomposites based on amorphous PET. J. Appl. Polym. Sci. 2010, 118, 3666-3672. [CrossRef]

3. Ludueña, L.; Vázquez, A.; Alvarez, V. Viscoelastic behavior of polycaprolactone/clay nanocomposites. J. Compos. Mater. 2012, 46, 677-689. [CrossRef]

4. Indennidate, L.; Cannoletta, D.; Lionetto, F.; Greco, A.; Maffezzoli, A. Nanofilled polyols for viscoelastic polyurethane foams. Polym. Int. 2010, 59, 486-491. [CrossRef]

5. Lionetto, F.; Maffezzoli, A. Rheological characterization of concentrarted nanoclay dispersions in an organic solvent. Appl. Rheol. 2009, 19, 23423.

6. Corcione, C.E.; Cavallo, A.; Pesce, E.; Greco, A.; Maffezzoli, A. Evaluation of the degree of dispersion of nanofillers by mechanical, rheological, and permeability analysis. Polym. Eng. Sci. 2011, 51, 1280-1285. [CrossRef]

7. Rahatekar, S.S.; Zammarano, M.; Matko, S.; Koziol, K.K.; Windle, A.H.; Nyden, M.; Kashiwagi, T.; Gilman, J.W. Effect of carbon nanotubes and montmorillonite on the flammability of epoxy nanocomposites. Polym. Degrad. Stab. 2010, 95, 870-879. [CrossRef]

8. Terenzi, A.; Vedova, C.; Lelli, G.; Mijovic, J.; Torre, L.; Valentini, L.; Kenny, J.M. Chemorheological behaviour of double-walled carbon nanotube-epoxy nanocomposites. Compos. Sci. Technol. 2008, 68, 1862-1868. [CrossRef]

9. Pan, F.; Peng, F.; Jiang, Z. Diffusion behavior of benzene/cyclohexane molecules in poly(vinyl alcohol)-graphite hybrid membranes by molecular dynamics simulation. Chem. Eng. Sci. 2007, 62, 703-710. [CrossRef]

10. Yu, A.; Ramesh, P.; Itkis, M.E.; Bekyarova, E.; Haddon, R.C. Graphite nanoplatelet-epoxy composite thermal interface materials. J. Phys. Chem. C 2007, 111, 7565-7569. [CrossRef]

11. Li, J.; Vaisman, L.; Marom, G.; Kim, J.K. Br treated graphite nanoplatelets for improved electrical conductivity of polymer composites. Carbon 2007, 45, 744-750. [CrossRef]

12. Steiner, S.; Busato, S.; Ermanni, P. Mechanical properties and morphology of papers prepared from single-walled carbon nanotubes functionalized with aromatic amides. Carbon 2012, 50, 1713-1719. [CrossRef]

13. Ganguli, S.; Roy, A.K.; Anderson, D.P. Improved thermal conductivity for chemically functionalized exfoliated graphite/epoxy composites. Carbon 2008, 46, 806-817. [CrossRef]

14. Yu, A.; Ramesh, P.; Sun, X.; Bekyarova, E.; Itkis, M.E.; Haddon, R.C. Enhanced thermal conductivity in a hybrid graphite nanoplatelet-Carbon nanotube filler for epoxy composites. Adv. Mater. 2008, 20, 4740-4744. [CrossRef]

15. Jović, N.; Dudić, D.; Montone, A.; Antisari, M.V.; Mitrić, M.; Djoković, V. Temperature dependence of the electrical conductivity of epoxy/expanded graphite nanosheet composites. Scr. Mater. 2008, 58, 846-849. [CrossRef]

16. Veca, L.M.; Meziani, M.J.; Wang, W.; Wang, X.; Lu, F.; Zhang, P.; Lin, Y.; Fee, R.; Connell, J.W.; Sun, Y. Carbon nanosheets for polymeric nanocomposites with high thermal conductivity. Adv. Mater. 2009, 21, 2088-2092. [CrossRef]

17. Liang, J.; Wang, Y.; Huang, Y.; Ma, Y.; Liu, Z.; Cai, J.; Zhang, C.; Gao, H.; Chen, Y. Electromagnetic interference shielding of graphene/epoxy composite. Carbon 2009, 47, 922-925. [CrossRef]

18. Zaman, I.; Phan, T.T.; Kuan, H.C.; Meng, Q.; La, L.T.B.; Luong, L.; Youssf, O.; Ma, J. Epoxy/graphene platelets nanocomposites with two levels of interface strength. Polymer 2011, 52, 1603-1611. [CrossRef]

19. Guo, Y.; Bao, C.; Song, L.; Yuan, B.; Hu, Y. In Situ polymerization of graphene, graphite oxide, and functionalized graphite oxide into epoxy resin and comparison study of on-the-flame behavior. Ind. Eng. Chem. Res. 2011, 50, 7772-7783. [CrossRef]

20. Shahil, K.M.F.; Balandin, A.A. Graphene-multilayer graphene nanocomposites as highly efficient thermal interface materials. Nano Lett. 2012, 12, 861-867. [CrossRef] [PubMed] 
21. Abdalla, M.; Dean, D.; Robinson, P.; Nyairo, E. Cure behavior of epoxy/MWCNT nanocomposites: The effect of nanotube surface modification. Polymer 2008, 49, 3310-3317. [CrossRef]

22. Kim, H.; Abdala, A.A.; Macosko, C.W. Graphene/polymer nanocomposites. Macromolecules 2010, 43, 6515-6530. [CrossRef]

23. Corcione, C.E.; Maffezzoli, A. Glass transition in thermosetting clay-nanocomposite polyurethanes. Thermochim. Acta 2009, 485, 43-48. [CrossRef]

24. Corcione, C.E.; Freuli, F.; Maffezzoli, A. The aspect ratio of epoxy matrix nanocomposites reinforced with graphene stacks. Polym. Eng. Sci. 2013, 53, 531-539. [CrossRef]

25. Choi, J.T.; Kim, D.H.; Ryu, K.S.; Lee, H.; Jeong, H.M.; Shin, C.M.; Kim, J.H.; Kim, B.K. Functionalized graphene sheet/polyurethane nanocomposites: Effect of particle size on physical properties. Macromol. Res. 2011, 19, 809-814. [CrossRef]

26. Chan, C.M.; Wu, J.; Li, J.X.; Cheung, Y.K. Polypropylene/calcium carbonate nanocomposites. Polymer 2002, 43, 2981-2992. [CrossRef]

27. Sumita, M.; Tsukumo, Y.; Miyasaka, K.; Ishikawa, K. Tensile yield stress of polypropylene composites filled with ultrafine particles. J. Mater. Sci. 1983, 18, 1758-1764. [CrossRef]

28. Tien, Y.I.; Wei, K.H. High-tensile-property layered silicates/polyurethane nanocomposites by using reactive silicates as pseudo chain extenders. Macromolecules 2001, 34, 9045-9052. [CrossRef]

29. Usuki, A.; Kojima, Y.; Kawasumi, M.; Okada, A.; Fukushima, Y.; Kurauchi, T.; Kamigaito, O. Synthesis of nylon 6-clay hybrid. J. Mater. Res. 1993, 8, 1179-1184. [CrossRef]

30. LeBaron, P.C.; Wang, Z.; Pinnavaia, T.J. Polymer-layered silicate nanocomposites: an overview. Appl. Clay Sci. 1999, 15, 11-29. [CrossRef]

31. Greco, A.; Maffezzoli, A.; Calò, E.; Massaro, C.; Terzi, R. An investigation into sintering of PA6 nanocomposite powders for rotational molding. J. Therm. Anal. Calorim. 2011, 109, 1493-1502. [CrossRef]

32. Bao, H.; Pan, Y.; Ping, Y.; Sahoo, N.G.; Wu, T.; Li, L.; Li, J.; Gan, L.H. Chitosan-functionalized graphene oxide as a nanocarrier for drug and gene delivery. Small 2011, 7, 1569-1578. [CrossRef] [PubMed]

33. Hu, F.; Chen, S.; Wang, C.; Yuan, R.; Yuan, D.; Wang, C. Study on the application of reduced graphene oxide and multiwall carbon nanotubes hybrid materials for simultaneous determination of catechol, hydroquinone, $p$-cresol and nitrite. Anal. Chim. Acta 2012, 724, 40-46. [CrossRef] [PubMed]

34. Hu, X.; Mu, L.; Wen, J.; Zhou, Q. Covalently synthesized graphene oxide-aptamer nanosheets for efficient visible-light photocatalysis of nucleic acids and proteins of viruses. Carbon 2012, 50, 2772-2781. [CrossRef]

35. Shen, J.; Yan, B.; Shi, M.; Ma, H.; Li, N.; Ye, M. Synthesis of graphene oxide-based biocomposites through diimide-activated amidation. J. Colloid Interface Sci. 2011, 356, 543-549. [CrossRef] [PubMed]

36. Sun, X.; Liu, Z.; Welsher, K.; Robinson, J.T.; Goodwin, A.; Zaric, S.; Dai, H. Nano-graphene oxide for cellular imaging and drug delivery. Nano Res. 2008, 1, 203-212. [CrossRef] [PubMed]

37. Liu, Z.; Robinson, J.T.; Sun, X.; Dai, H. PEGylated nanographene oxide for delivery of water-insoluble cancer drugs. J. Am. Chem. Soc. 2008, 130, 10876-10877. [CrossRef] [PubMed]

38. Zuo, P.P.; Feng, H.F.; Xu, Z.Z.; Zhang, L.F.; Zhang, Y.L.; Xia, W.; Zhang, W.Q. Fabrication of biocompatible and mechanically reinforced graphene oxide-chitosan nanocomposite films. Chem. Cent. J. 2013, 7, 39. [CrossRef] [PubMed]

39. Rinaudo, M. Chitin and chitosan: Properties and applications. Prog. Polym. Sci. 2006, 31, $603-632$. [CrossRef]

40. Raucci, M.G.; Alvarez-Perez, M.A.; Demitri, C.; Giugliano, D.; de Benedictis, V.M.; Sannino, A.; Ambrosio, L. Effect of citric acid crosslinking cellulose-based hydrogels on osteogenic differentiation. J. Biomed. Mater. Res. A 2015, 103, 2045-2056. [CrossRef] [PubMed]

41. Dimida, S.; Demitri, C.; de Benedictis, V.M.; Scalera, F.; Gervaso, F.; Sannino, A. Genipin-cross-linked chitosan-based hydrogels: Reaction kinetics and structure-related characteristics. J. Appl. Polym. Sci. 2015. [CrossRef]

42. Madaghiele, M.; Sannino, A.; Ambrosio, L.; Demitri, C. Polymeric hydrogels for burn wound care: Advanced skin wound dressings and regenerative templates. Burn Trauma 2014, 2, 153-161. [CrossRef]

43. Demitri, C.; Giuri, A.; Raucci, M.G.; Giugliano, D.; Madaghiele, M.; Sannino, A.; Ambrosio, L. Preparation and characterization of cellulose-based foams via microwave curing. Interface Focus 2014. [CrossRef] [PubMed] 
44. Pan, Y.; Wu, T.; Bao, H.; Li, L. Green fabrication of chitosan films reinforced with parallel aligned graphene oxide. Carbohydr. Polym. 2011, 83, 1908-1915. [CrossRef]

45. Yang, X.; Tu, Y.; Li, L.; Shang, S.; Tao, X. Well-dispersed chitosan/graphene oxide nanocomposites. ACS Appl. Mater. Interfaces 2010, 2, 1707-1713. [CrossRef] [PubMed]

46. Brugnerotto, J.; Lizardi, J.; Goycoolea, F.M.; Argüelles-Monal, W.; Desbrieres, J.; Rinaudo, M. An infrared investigation in relation with chitin and chitosan characterization. Polymer 2001, 42, 3569-3580. [CrossRef]

47. Kumar, M.N.V.R. A review of chitin and chitosan applications. React. Funct. Polym. 2000, 46, 1-27. [CrossRef]

48. Datta, P.; Dhara, S.; Chatterjee, J. Hydrogels and electrospun nanofibrous scaffolds of N-methylene phosphonic chitosan as bioinspired osteoconductive materials for bone grafting. Carbohydr. Polym. 2012, 87, 1354-1362. [CrossRef]

49. Meng, S.; Zhang, Z.; Rouabhia, M.J. Accelerated osteoblast mineralization on a conductive substrate by multiple electrical stimulation. Bone Min. Metab. 2011, 29, 535-544.

50. Corcione, C.E.; Maffezzoli, A. Transport properties of graphite/epoxy composites: Thermal, permeability and dielectric characterization. Polym. Test. 2013, 32, 880-888.

51. Mauro, M.; Acocella, M.R.; Corcione, C.E.; Maffezzoli, A.; Guerra, G. Catalytic activity of graphite-based nanofillers on cure reaction of epoxy resins. Polymer 2014, 55, 5612-5615. [CrossRef]

52. Chen, K.; Xue, D. Preparation of colloidal graphene in quantity by electrochemical exfoliation. J. Colloid Interface Sci. 2014, 436, 41-46. [CrossRef] [PubMed]

53. Gayathri, S.; Jayabal, P.; Kottaisamy, M.; Ramakrishnan, V. Synthesis of few layer graphene by direct exfoliation of graphite and a Raman spectroscopic study. Aip Adv. 2014, 4, 27116. [CrossRef]

54. Mallakpour, S.; Madani, M. A general and efficient route to covalently surface modification of MWCNTs by dopamine and their synergistic reinforcing effects in chitosan films. Prog. Org. Coatings 2015, 85, 131-137. [CrossRef]

55. Tian, H.; Tagaya, H. Preparation, characterization and mechanical properties of the polylactide/perlite and the polylactide/montmorillonite composites. J. Mater. Sci. 2007, 42, 3244-3250. [CrossRef]

(C) 2015 by the authors; licensee MDPI, Basel, Switzerland. This article is an open access article distributed under the terms and conditions of the Creative Commons by Attribution (CC-BY) license (http:/ / creativecommons.org/licenses/by/4.0/). 